Vol II. No. 2, Maret 2018, hlm. $171-179$

Available online at www.jurnal.una.ac.id/indeks/jmp

\title{
PERBEDAAN KEMAMPUAN PEMECAHAN MASALAH MATEMATIKA ANTARA PEMBELAJARAN PROBLEM BASED LEARNING DENGAN TIPE JIGSAW
}

\author{
Mardiana $^{1}$,Dewi Purnama ${ }^{2}$ \\ STMIK Budi Daya Binjai \\ e-mail : dianannst18@gmail.com
}

\begin{abstract}
This study aims to examine the differences in students' mathematics problem solving skills in grade VIII MTs.N Besitang Lesson Year 2017/2018 with a sample of 60 students consisting of 30 students for experimental class 1 and 30 students for experimental class 2. The research method used is quasi experiment. The research design used in this research is posstestonly design.From the data processing obtained the average value of experimental class1 (Problem based learning) on the result of posttest problem solving = 25.567 and on the result of posttest experimental class 2 (jigsaw) $=23,667$. From the average value difference, it can be seen that the average problem solving ability of PBL students' mathematics problem is superior to the average problem solving ability of students mathematics using jigsaw type learning. The result of normality test and homogeneity test shows that the data is normal and homogeneous distribution. Based on the results of ANOVA analysis test on KAM data and experimental class posttest obtained Fcount> Ftable $(5,028>4,020)$ so it can be concluded that the problem solving ability of students with learning problem based learning more effectively used in grade VIII students MTs.NBesitang Lesson Year 2017/2018
\end{abstract}

Keywords: Problem-based learning and jigsaw learning model, Student Mathematics Problem Solving Ability.

\begin{abstract}
Abstrak
Penelitian ini bertujuan untuk melihat perbedaan kemampuan pemecahan masalah matematika siswa kelas VIIIMTs.N Besitang Tahun Pelajaran 2017/2018 dengan sampel penelitian berjumlah 60 siswa yang terdiri dari 30 siswa untuk kelas eksperimen 1 dan 30 siswa untuk kelas eksperimen2. Metode penelitian yang digunakan adalah quasi eksperimen. Desain penelitian yang dipakai dalam penelitian ini adalah posstest only design. Dari pengolahan data diperoleh nilai rata-rata kelas eksperimen1 (Problem basedlearning) pada hasil postestpemecahan masalah $=25,567$ dan pada hasil posttestkelas eksperimen2(jigsaw) $=23,667$. Dari perbedaan nilai rata-rata tersebut terlihat bahwa rata-rata kemampuan pemecahan masalah matematika siswa kelas PBL lebih unggul dibandingkan dengan rata-rata kemampuan pemecahan masalah matematika siswa yang menggunakan pembelajarantipe jigsaw. Hasil perhitungan uji normalitas dan uji homogenitas menunjukkan bahwa data berdistribusi normal dan homogen. Berdasarkan hasil uji analisis ANAVA pada dataKAMdan posttestkelas eksperimen diperoleh $\mathrm{F}_{\text {hitung }}>\mathrm{F}_{\text {tabel }}(5,028>4,020)$ sehingga dapat disimpulkan bahwa kemampuan pemecahan masalah siswa dengan pembelajran Problem based learning lebih efektif digunakan pada siswa kelas VIII MTs.N Besitang Tahun Pelajaran 2017/2018
\end{abstract}

Kata kunci : Model pembelajaran Problem based learning dan jigsaw, Kemampuan Pemecahan Masalah Matematika Siswa. 
Vol II. No. 2, Maret 2018, hlm. 171 - 179

Available online at www.jurnal.una.ac.id/indeks/jmp

Dalam era globalisasi seperti ini, hampir semua orang berasumsi bahwa pendidikan merupakan bidang yang sangat penting bagi kemajuan dan pembangunan suatu bangsa. Arif Rohman mengemukakan bahwa pendidikan dapat diartikan sebagai proses perubahan sikap dan tingkah laku seseorang atau kelompok dalam usaha mendewasakan manusia melalui proses pengajaran dan pelatihan.

Setiap manusia sangat membutuhkan pendidikan karena pendidikan sangat berpengaruh dalam pengembangan potensi diri yang dimilikinya, dengan mengubah sikap dan tingkah laku ke arah yang lebih baik sesuai nilai-nilai yang berlaku dalam masyarakat. Pendidikan merupakan faktor utama dalam pembentukan pribadi dan sumber daya manusia.Pendidikan sangat berperan dalam membentuk baik atau buruknya pribadi dan kualitas sumber dayamanusia.Memasuki abad ke-21, sistem pendidikan nasional menghadapi tantangan yang sangat kompleks dalam menyiapkan kualitas sumber daya manusia (SDM) yang mampu bersaing dalam menghadapi tuntutan di era globalisasi ini. Dimana di era globalisasi ini sumber daya manusia (SDM) yang bermutulah yang akan dapat bersaing. Pada hakikatnya, pendidikan merupakan suatu usaha manusia untuk mendapatkan ilmu pengetahuan dan informasi dari berbagai sumber dan tempat. Oleh karena itu, melalui pendidikan kita dapat menyiapkan sumber daya manusia yang mampu menguasai ilmu pengetahuan dan teknologi guna memenuhi kebutuhannya dan menjawab berbagai tantangan yang dihadapi dalam kehidupan masyarakat yang dinamis. Menyadari akan hal tersebut, pemerintah sangat serius menangani bidang pendidikan, sebab dengan sistem pendidikan yang baik diharapkan muncul generasi penerus bangsa yang bermutu dan berkualitas yang siap pakai di era globalisasi ini. Salah satunya melakukan perubahan kurikulum untuk memperbaiki kualitas pendidikan dimana kurikulum yang dimaksudkan adalah Kurikulum Tingkat Satuan Pendidikan (KTSP). KTSP adalah kurikulum operasional yang disusun oleh dan dilaksanakan di masingmasing satuan pendidikan dengan mengacu kepada prinsip-prinsip yang telah ditetapkan oleh pemerintah seperti berpusat pada potensi, perkembangan, kebutuhan, dan kepentingan peserta didik dan lingkungannya beragam dan terpadu; tanggap terhadap perkembangan ilmu pengetahuan, teknologi dan seni; relevan dengan kebutuhan kehidupan; menyeluruh dan berkesinambungan; belajar sepanjang hayat; seimbang antara kepentingan nasional dan kepentingan daerah. Dimana tujuan pendidikan menengah dalam kurikulum ini adalah untuk meningkatkan kecerdasan, pengetahuan, kepribadian, akhlak mulia, serta keterampilan untuk hidup mandiri dan mengikuti pendidikan lebih lanjut.

Matematika merupakan salah satu mata pelajaran yang harus dipelajari dan dipahami oleh siswa karena memegang peranan penting dalam pengembangan dan kemajuan ilmu pengetahuan dan teknologi. Tanpa peranannya, mungkin saja perkembangan ilmu pengetahuan akan berhenti berkembang. Mem- 
Vol II. No. 2, Maret 2018, hlm. 171 - 179

Available online at www.jurnal.una.ac.id/indeks/jmp

pelajari matematika sangat perlu bagi seseorang, seperti yang dikemukakan oleh Cockroft Matematika perlu diajarkan kepada siswa karena:

1. selalu digunakan dalam segala seni kehidupan,

2. semua bidang studi memerlukan keterampilan matematika yang sesuai,

3. merupakan sarana komunikasi yang kuat, singkat, dan jelas,

4. dapat digunakan untuk menyajikan informasi dalam berbagai cara,

5. meningkatkan kemampuan belajar logis, ketelitian, dan kesadaran keruangan,

6. memberikan kepuasan terhadap usaha memecahkan masalah yang menantang. Hal ini juga menunjukkan betapa matematika memberikan siswa banyak pengetahuan dan sarana untuk meningkatkan kemampuan belajar logis dalam memecahkan masalah yang menantang dalam kehidupan sehari-hari.

Adapun Tujuan dari pembelajaran matematika adalah agar siswa memiliki kemampuan sebagai berikut:

(1) Memahami konsep matematika, menjelaskan keterkaitan antarkonsep dan mengaplikasikan konsep atau algoritma, secara luwes, akurat, efisien, dan tepat, dalam

pemecahan masalah; (2) Menggunakan penalaran pada pola dan sifat, melakukan manipulasi matematika dalam membuat generalisasi, menyusun bukti, atau menjelaskan gagasan dan pernyataan matematika;(3) Memecahkan masalah yang meliputi kemampuan memahami masalah, merancang model matematika,(4) Mengomunikasikan gagasan dengan simbol, tabel, diagram, atau media lain untuk memperjelas keadaan atau masalah; (5) Memiliki sikap menghargai kegunaan matematika dalam kehidupan, yaitu memiliki rasa ingin tahu, perhatian, dan minat dalam mempelajari matematika, serta sikap ulet dan percaya diri dalam pemecahan masalah.

Beberapa indikator pemecahan masalah matematis yang dapat digunakan adalah: (1) menerapkan dan menggunakan berbagai strategi yang tepat untuk memecahkan masalah; (2) memecahkan masalah matematika maupun dalam konteks lain yang berhubungan dengan kehidupan sehari-hari; (3) menjelaskan atau menginterpretasikan hasil sesuai permasalahan asal, serta memeriksa kebenaran hasil atau jawaban.

Secara garis besar, kemampuan dasar matematika dapat diklasifikasikan dalam lima standar yaitu kemampuan: 1) mengenal, memahami dan menerapkan konsep, prosedur, prinsip dan idea matematika; 2) menyelesaikan masalah matematik (mathematical problem solving); 3) bernalar matematik (mathematical reasoning); 4) melakukan koneksi matematik (mathematical connection), dan 5) komunikasi matematik (mathematical communication).

Problem Based Learning (PBL) atau istilah lainnya adalah pembelajaran berbasis masalah merupakan model pembelajaran yang berpusat pada siswa, dimana siswa harus belajar untuk menerapkan pengetahuan, bukan hanya memperoleh pengetahuan serta aktif membangun pengetahuan.Proses belajar yang dilakukan siswa 
Vol II. No. 2, Maret 2018, hlm. 171 - 179

Available online at www.jurnal.una.ac.id/indeks/jmp

menekankan pada memotivasi untuk bertanggung jawab atas belajar dan mengembangkan kemampuan penyelidikan mereka dalam proses penalaran berdasarkan masalah dunia nyata.

Disamping itu, PBL dapat mendorong siswa untuk melakukan evaluasi sendiri baik terhadap hasil maupun proses belajarnya, mengembangkan kemampuan siswa untuk berfikir kritis dan mengem-bangkan kemampuan mereka untuk menyesuaikan dengan pengetahuan baru, memberikan kesempatan bagi siswa untuk mengaplikasikan pengetahuan yang mereka miliki dalam dunia nyata, mengembangkan minat siswa untuk secara terus menerus belajar sekalipun belajar pada pendidikan formal telah berakhir dan memudahkan siswa dalam menguasai konsep-konsep yang dipelajari guna memecahkan masalah dunia nyata.

Selain model pembelajaran PBL, ada solusi lain dari model pembelajaran yang akan digunakan untuk menanamkan pemecahan masalah matematis pada diri siswa yaitu model pembelajaranjigsaw. Model pembelajaran kooperatif tipe Jigsaw merupakan pembelajaran yang diawali dengan tugas membaca/ mempelajari bahan ajar yang berbeda-beda dalam satu kelompok lalu anggota kelompok dipecah dan dikelompokkan menurut bahan ajar yang didapat. Dalam kelompok tersebut, siswa berdiskusi terkait bahan ajarnya setelah itu kembali ke kelompok awal dan menjelaskan ke anggota yang lain terkait tugasnya kemudian siswa diberi kuis tentang seluruh bahan ajar, dan skor kuis tersebut menjadi skor kelompok.
Menurut Rusman "Model pembelajaran kooperatif tipe Jigsaw yaitu sebuah model pembelajaran yang menitik beratkan pada kerja kelompok siswa dalam bentuk kelompok kecil. Dalam model pembelajaran ini siswa memiliki banyak kesempatan untuk mengemukakan pendapat dan mengolah informasi yang diperoleh, serta dapat meningkatkan keterampilan berkomunikasi.

Selain itu menuerut Isjoni "Dalam model pembelajaran kooperatif tipeJigsaw siswa belajar dalam kelompok kecil yang terdiri dari empat sampai enam orang, heterogen dan bekerjasama saling ketergantungan yang positif dan bertanggungjawab secara mandiri. Jumlah siswa yang bekerjasama dalam masing-masing kelompok harus dibatasi, agar kelompokkelompok yang terbentuk dapat bekerjasama secara efektif, karena suatu ukuran kelompok mempengaruhi kemampuan produktivitasnya.

Metode tipe Jigsaw adalah salah satu teknik pembelajaran kooperatif. Siswa yang memiliki tanggung jawab lebih besar dalam pelaksanaan pembelajaran, dan bukan gurunya. Jigsaw telah di kembangkan dan diuji coba oleh Eliot Aroson dan teman - temannya di Universitas Texas, dan diadopsi oleh Slavin dan teman-temannya di Universitas John Hopkins. Pembelajaran menggunakan Jigsaw melibatkan semua peserta didik yang ada di kelas. Tujuan dari metode ini adalah mengembangkan kerja tim, keterampilan belajar kooperatif dan penguasaan materi. Kegiatan-ke- 
Vol II. No. 2, Maret 2018, hlm. 171 - 179

Available online at www.jurnal.una.ac.id/indeks/jmp

giatan yang dilakukan dalam metode Jigsaw antara lain :

a) Listening (Mendengarkan), siswa aktif mendengarkan dalam materi yang dipelajari dan mampu memberikan pengajaran pada kelompok aslinya.

b) Speaking-stident (berkata), akan menjadikan siswa bertanggung jawab speakingstident (berkata), akan menjadikan siswa bertanggung jawab menerima pengetahuan dari menerima pengetahuan dari kelompok dan menyampaikannya kepada pendengar baru dari kelompok aslinya.

c) Kerjasama setiap anggota dari tiap kelompok bertanggung jawab untuk sukses dari yang lain dalam kelompok.

d) Refleksi pemikiran dengan berhasil melengkapu, menyelesaikan kegiatan dalam kelompok asli, harus ada pemikiran reflektif yang menerangkan tentang yang dipelajari dalam kelompok ahli.

Berdasarkan penjelasan di atas dirasa perlu untuk mengungkapkan apakah selain kemampuan awal matematika siswa, model pembelajaran PBL dan model pembelajaran jigsaw juga memiliki perbedaan konstribusi terhadap kemampuan pemecahan masalah matematis siswa. Kemudian bagaimana proses penyelesaian jawaban siswa terhadap tes kemampuan pemecahan masalah matematis yang diberikan pada siswa setelah diberi model pembelajaran PBL dengan jigsaw. Hal inilah yang mendorong dilakukan suatu penelitian yang memfokuskan diri dengan judul "Perbedaan kemampuan pemecahan masalah matematis antara siswa yang diberi model pembelajaran PBL dengan jigsaw di MTs Negeri Besitang". Dari permasalahan yang telah diuraikan dapat diidentifikasikan yaitu: Hasil belajar matematika siswa masih rendah, Kemampuan pemecahan masalah matematis siswa masih rendah sehingga siswa tidak dapat menyelesaikan soal yang menuntut pemecahan masalah, Pembelajaran yang diberikan guru hanya menyampaikan materi tanpa memperhatikan makna yang diterima oleh siswa, Pembelajaran yang dilakukan guru belum bervariasi, Guru kurang memperhatikan kemampuan awal siswa yang berbeda-beda.Adapun yang menjadi rumusan masalah dalam penelitian ini adalah : 1. Apakah terdapat perbedaan kemampuan pemecahan masalah matematika siswa antara siswa yang diberi pembelajaran Problem Based Learning dengan pembelajaran tipe jigsaw ?

2. Apakah terdapat interaksi antara model pembelajaran dengan kemampuan awal matematika siswa terhadap kemampuan pemecahan masalah matematika?

Tujuan penelitian ini adalah : 1 . Untuk mengetahui Perbedaan kemampuan pemecahan masalah matematika siswa yang diberi pembelajaran Problem Based Learning dengan pembelajaran jigsaw. 2.Untuk mengetahui interaksi antara model pembelajaran dengan kemampuan awal matematika siswa terhadap kemampuan pemecahan masalah matematika. 
Vol II. No. 2, Maret 2018, hlm. 171 - 179

Available online at www.jurnal.una.ac.id/indeks/jmp

\section{METODE}

Penelitian ini merupakan penelitian eksprimen dengan jenis penelitiannya adalah quasi eksperiment (eksprimen semu). Dimana dalam penelitian ini terdapat dua kelompok eksperimen (diberi perlakuan). Kelompok eksperimen pertama diberi model pembelajaran PBL dan kelompok eksperimen kedua diberi model pembelajaran jigsaw yang dilakukan di MTs. Negeri Besitang T.P 2017/2018.

Sampel dalam penelitian ini diambil dengan teknik pengambilan sampel secara acak (random sampling), akan diambil sebanyak dua kelas. Dimana pengambil sampel dilakukan dengan cara diundi dan terambil dua kelas yaitu kelas VIII-1 yang terdiri dari 30 siswa dan kelasVIII-2 yang terdiri dari 30 siswa.

Tabel 1 Desain Penelitian

\begin{tabular}{lll}
\hline Kelas & Perlakuan & Postest \\
\hline PBL & $\mathrm{X}_{1}$ & $\mathrm{Y}_{2}$ \\
\hline jigsaw & $\mathrm{X}_{2}$ & $\mathrm{Y}_{2}$ \\
\hline
\end{tabular}

Keterangan :

$\mathrm{X}_{1}$ : Model pembelajaran PBL

$\mathrm{X}_{2} \quad$ : Model pembelajaranjigsaw

$\mathrm{Y}_{2} \quad$ :Posttest (tes akhir kemampuan pemecahan masalah matematis)

Sebelum soal diberikan kepada siswa, maka soal tersebut harus diuji validitasya.Validitas ditetapkan berdasarkan kesesuaian antara kisi-kisi soal dengan butir soal. Sebelum instrumen diujicobakan, dilakukan validasi terhadap perangkat dan instrumen soal oleh beberapa ahli.Ahli yang dimaksud dalam hal ini adalah validator yang kompeten meliputi dosen dua orang dosen matematika STKIP Budidaya Binjai, dan dua orang guru matematika.Validasi perangkat difokuskan pada isi, format, bahasa serta kesesuaian karakteristik model pembelajaran PBL dan model pembelajaran jigsaw. Hasil validasi terhadap perangkat pembelajaran yaitu Rencana Pelaksanaan Pembelajaran (RPP) dan Lembar Kerja Siswa (LKS). Setelah dilakukan tahap validasi oleh para ahli dan revisi, maka perangkat dan instrumen siap untuk diujicobakan. Selanjutnya diadakan tahap uji coba instrumen kepada siswa yang berada di luar objek penelitian yaitu siswa yang telah mempelajari materi yang digunakan.

\section{HASIL DAN PEMBAHASAN}

Berdasarkan hasil penelitian para ahli, dilakukan revisi sesuai saran yang diberikan guna penyempurnaan perangkat penelitian. Selanjutnya dilakukan analisis validitas, daya pembeda, tingkat kesukaran, dan reliabilitas soal uraian sebagai berikut:

Distribusi tabel t untuk $\alpha=0,05$ dan derajat kebebasan $d k=n-2$. Membuat kesimpulan, dengan kriteria pengujian sebagai berikut: Jika $t_{\text {hitung }}>t_{\text {tabel }}$, butir soal valid, atau Jika $t_{\text {hitung }} \leq t_{\text {tabel }}$, butir soal tidak valid.

Untuk menentukan valid atau tidaknya suatu butir tes makathitung perlu dibandingkan dengan $t_{\text {tabel, jika }}$ $t_{\text {hitung }}>t_{\text {tabel }}$ dengan $\mathrm{t}_{\text {tabel }}=\mathrm{t}_{(1-} \alpha_{(\mathrm{dk})}$ untuk $\mathrm{dk}=\mathrm{N}-2$ dan $\alpha($ taraf 
Jurnal

MATEMATICS PAEDAGOGIC

Vol II. No. 2, Maret 2018, hlm. 171 - 179

Available online at www.jurnal.una.ac.id/indeks/jmp

signifikan 5\%) maka soal tersebut valid, namun sebaliknya jika $\mathrm{t}_{\text {hitung }}<$ $\mathrm{t}_{\text {tabel }}$ maka soal tersebut tidak valid. Untuk hasil Deskripsi Posttest Kemampuan Pemecahan Masalah Matematika

Tabel 2. Deskripsi PostTest

\begin{tabular}{lllllll}
\hline Kelas & $\begin{array}{l}\text { Skor } \\
\text { Ideal }\end{array}$ & $\mathbf{N}$ & $\boldsymbol{x}_{\min }$ & $\boldsymbol{x}_{\max }$ & $\bar{x}$ & SB \\
\cline { 1 - 6 } PBL & & 30 & 17 & 33 & 25,6 & 4,5 \\
\cline { 3 - 6 } & \multirow{2}{*}{36} & 30 & 17 & 31 & 23,7 & 3,9
\end{tabular}

Dapat disimpulkan bahwa hasil uji normalitas nilai kemampuan awal matematika siswa

Tabel 3. Tabel normalitas

\begin{tabular}{llll}
\hline Kelas & $\mathbf{N}$ & $\mathbf{L}_{\mathbf{0}}$ & $\mathbf{L}_{\text {tabel }}$ \\
\hline PBL & 30 & 0,157 & 0,161 \\
\hline Jigsaw & 30 & 0,142 & 0,161 \\
\hline \multicolumn{5}{c}{ Dari hasil perhitungan yang }
\end{tabular}
disajikan pada tabel 3 di atas dapat dilihat bahwa nilai $\mathrm{L}_{0}$ berturut adalah 0,157dan 0,142 untuk kelas PBL dan kelas jigsaw.Nilai $\mathrm{L}_{0}$ kedua kelas lebih kecil dari $\mathrm{L}_{\text {tabel}}$, sehingga $\mathrm{H}_{0}$ yang menyatakan data berdistribusi normal untuk kelas PBL dan kelas jigsaw dapat diterima. Dengan kata lain data untuk kelas PBL dan kelas jigsaw mempunyai data yang berdistribusi normal.

Kriteria untuk pengujian homo-genitas dengan menggunakan uji-F adalah terima $\mathrm{H}_{0}$ jika $\mathrm{F}_{\text {hitung }}<$ $F_{\text {tabel }}$ dan tolak $\mathrm{H}_{0}$ jika $F_{\text {hitung }}>F_{\text {tabel. }}$. Berikut Hasil Uji Homogenitas Posttest Kemampuan Pemecahan Masalah Matematika.

Tabel 4. Homoenitas postest

\begin{tabular}{llll}
\hline Kelas & Varians $\left(\mathbf{s}^{\mathbf{2}}\right)$ & $\mathbf{F}_{\text {hitung }}$ & $\mathbf{F}_{\text {tabel }}$ \\
\hline PBL & 20,530 & & \\
\hline Jigsaw & 15,126 & 1,357 & 1,841 \\
\hline
\end{tabular}

Untuk Hasil Perhitungan ANAVA Manual Posttest Kemampuan Pemecahan Masalah Matematika.

Tabel 5. Hasil ANAVA

\begin{tabular}{llllll} 
Sumber & DK & JK & RJK & $\mathbf{F}_{\text {hi }}$ & $\begin{array}{l}\mathbf{F}_{\text {tabel }} \\
(\mathbf{0 , 0 5})\end{array}$ \\
\hline Pembel & 1 & 54,15 & 54,15 & 5,03 & 4,020 \\
KAM & 2 & 324,84 & 162,42 & 15,1 & 3,168 \\
Pemb*KAM & 2 & 127,65 & 63,826 & 5,92 & 3,168 \\
Galat & 54 & 581,54 & 10,770 & & \\
\hline Total & 59 & 1088,1 & & & \\
\hline
\end{tabular}

Dari hasil perhitungan yang disajikan pada tabel 5 di atas dapat dilihat pada pembelajaran bahwa $F_{\text {hitung }}>\mathrm{F}_{\text {tabel }}$ yaitu 5,03>4,020 maka untuk uji hipotesis 1 tolak $\mathrm{H}_{0}$ terima $\mathrm{H}_{\mathrm{a}}$, yaitu terdapat perbedaan kemampuan Pemecahan masalah matematika siswa yang diberi model pembelajaran PBL dengan jigsaw.

\section{SIMPULAN}

Berdasarkan hasil analisis, temuan dan pembahasan yang telah dikemukakan pada bab sebelumnya diperoleh beberapa kesimpulan yang berkaitan dengan model pembelajaran Problem Based Learning dengan jigsaw, Simpulan tersebut sebagai berikut : Terdapat perbedaan kemampuan pemecahan masalah matematika antara siswa yang diberi model pembelajaran Problem Based Learning dengan jigsaw, dengan $\mathrm{F}_{\text {hitung }}>\mathrm{F}_{\text {tabel }}$ yaitu $5,028>4,020$. Hal ini dapat dilihat dari dampak pembelajaran yang ditinjau dari skor rata-rata posttest kemampuan pemecahan masalah matematika siswa yang diberi model pembelajaran PBL $(25,567)$ lebih tinggi dibanding skor rata-rata posttest kemampuan pemecahan masalah matematika untuk kelas 
Vol II. No. 2, Maret 2018, hlm. 171 - 179

Available online at www.jurnal.una.ac.id/indeks/jmp

yang diberi model pembelajaran jigsaw $(23,667)$. Hal ini juga dapat diartikan bahwa aktifitas siswa dalam pembelajaran ini membuat siswa menjadi lebih kreatif dan memiliki semangat yang tinggi dalam memecahkan masalah.

Berdasarkan kesimpulan diatas dan pengalaman dalam proses belajar mengajar yang terjadi selama penelitian, maka penulis dapat memberikan saran-saran sebagai berikut:

\section{Kepada Guru}

Hendaknya model pembelajaran ini terus dikembangkan di lapangan yang membuat siswa terlatih dalam menyelesaikan masalah melalui proses pemahaman konsep matematik. dengan kemampuan pemecahan masalah matematika.

\section{DAFTAR RUJUKKAN}

Branca N.A. 1980. Problem Solving as A Goal, Process, and Basic Skills.In Problem Solving in School Mathematics: 1980 Yearbook edited by S. Krulik and R.E. Reys. Reston, VA: NCTM.

Kadir, Abdul. (2008). Tuntunan Praktis Belajar. Yogjakarta.

Abdurrahman, M. 2012. Anak Berkesulitan Belajar Teori, Diagnosis dan Remediasinya. Jakarta: Rineka cipta

Agustina N, (2011), Media dan Pembelajaran Palembang: Universitas SriWijaya.

Alam, B. I. 2012. Peningkatan Kemampuan Pemahaman dan Komunikasi Matematika Siswa
2. Kepada Lembaga Terkait Pembelajaran dengan model pembelajaran PBL dan model pembelajaran jigsaw, masih sangat asing bagi guru dan siswa terutama pada guru dan siswa di daerah, oleh karena itu perlu disosialisasikan oleh sekolah dengan harapan dapat merubah ke-mampuan belajar siswa ke arah yang lebih baik.

3. Kepada Peneliti Lanjutan

Penelitian ini hanya terbatas pada model pembelajaran PBL dengan jigsaw sertamateri bentuk aljabar di kelas VIII terhadap kemampuan pemecahan masalah matematika siswa. Disarankan untuk peneliti selanjutnya agar membandingkan model pembelajaran tersebut dengan kemampuan matematis yang lain.

SD Melalui Pendekatan Realistic Mathematics Eucation (RME). Prosiding. ISBN: $\quad 978-979-16353-8-7$. [Diakses 28 Agustus 2015]

Arends, R.I. (2008). Leraning To Teach (Belajar untuk Mengajar) Buku Satu Edisi Ketujuh. Yogyakarta: Pustaka pelajar.

Rohman, Arif. (2009). Memahami Pendidikan dan Ilmu Pendidikan. Yogyakarta: LaksBang Mediatama.

Badan Standar Nasional Pendidikan. 2006. Panduan Penyusunan Kurikulum Tingkat Satuan Pendidikan Jenjang Pendidikan Dasar dan 
Vol II. No. 2, Maret 2018, hlm. 171 - 179

Available online at www.jurnal.una.ac.id/indeks/jmp

Menengah [Diakses 11 September 2015]

Brodeur, D. R. 2002. Problem-Based Learning in Aerospace Engineering Education Massachusetts Institute of Technology. Proceedings of the 2002 American Society for Engineering Education Annual Conference \& Exposition Copyright 2002, American Society for Engineering Education. [diakses 3 September 2015 ]

Dahar, R. W. 2006. Teori-teori Belajar \& Pembelajaran. Jakarta: Erlangga

Depdiknas. 2006. Peraturan Menteri Pendidikan Nasional Nomor 22 Tahun 2006 Tentang Standar Isi. Jakarta: direktorat jenderal managemen pendidikan dasar dan menengah.[online]. [Diakses 5 September 2015]

Herman, T. 2008. Strategi Pemecahan Masalah (ProblemSolving) dalam Pembelajaran Matematika. Makalah disajikan dalam Kegiatan Asisten Guru Madrasah Ibtidaiyah dan Tsanawiyah Jawa Barat Tanggal 28 September s.d 3 Oktober 2000. . [Diakses 12 Oktober 2015]

Hmelo, C. E. 2002. Problem-Based Learning: What and How Do Students Learn?. Educational Psychology Review, Vol. 16, No. 3, September 2004 ( C ${ }^{\circ}$ 2004). [Diakses 8 September 2015]

Hidayat, T. N. 2011. Implementasi Teori Gestalt pada Proses
Pembelajaran. JURNAL FALASIFA. Vol. 2 No. 1 Maret 2011.. [Diakses 8 September 2015]

Hudojo, H. 2001. Pengembangan Kurikulum dan Pembelajaran Matematika. Bandung: Jurusan Pendidikan Matematika Fakultas Matematika dan ilmu Pengetahuan Alam Universitas Negeri Malang

Isjoni (2009). Cooperative Learning Efektivitas Pembelajaran Kelompok. Bandung : Alfabeta.

Kuklthau. 2013. Capacity Building Series K-12. Support every child reach every student. ISSN: 19138490 [Online]. [Diakses 16 Agustus 2015]

Mathews, J. 2007. Problem-Based Learning and Adult English Language Learners Center for Adult English Language Acquisition, Center for Applied Linguistics. Center for Applied Linguistics 4646 40th Street NW Washington, April 2007 DC 20016-1859. [online].

[Diakses 5 September 2015]

Syah , Muhibbin (2006) Psikolog Pendidikan. Bandung; PT Remaja Rosda Karya

NCTM. (2000), Principles and Standarts for Mathematics, Reaston, VA: NCTM

[Diakses 5 September 2015]

Nurhadi, dkk. 2004. Pembelajaran Kontekstual dan Penerapannya dalam KBK. Malang; UM Press 